\title{
Survive and Thrive: Field Research in Authoritarian Southeast Asia
}

\author{
Lee Morgenbesser (D) and Meredith L. Weiss ${ }^{\mathrm{b}}$

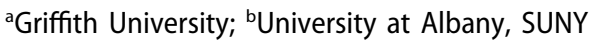

\begin{abstract}
The literature on field research methods has focused almost exclusively on the strategies available to scholars working in democracies. By comparison, there has been scant guidance for those working in authoritarian regimes. This is despite the distinct set of challenges that arise where civil liberties and political rights are not consistently or well protected. The purpose of this article is to address this deficit. Drawing on the region of Southeast Asia as a natural laboratory for comparative analysis, it offers guidance on how to successfully conduct archival research, carry out interviews and undertake participant observation under authoritarianism. The resulting conclusions are applicable to the pursuit of primary research by scholars at all career levels and in other regions of the world.
\end{abstract}

\section{KEYWORDS}

Authoritarianism; field research; methodology; Southeast Asia

\section{Introduction}

Field research is an indispensable methodological tool for many political scientists. It holds the capacity to yield rich data, generate analytical insights and inspire informed iteration among practitioners at all career levels (Feldman, Bell, \& Berger, 2003; Perecman \& Curran, 2006; Kapiszewski, Maclean, \& Read, 2015). Despite these known benefits, the challenges and opportunities of applying this methodology vary significantly across different political systems. The existing scholarship on field research - a limited genre, at best - has tended to presume the setting to be liberal democratic regimes, rather than the less accessible, secure and transparent setting of authoritarian regimes. This tendency inadvertently obliges scholars, especially graduate students, to rely on "one size fits all" recommendations that are often not applicable to countries that are either inhospitably sensitive or dangerously hostile to political research. In consequence, the discipline of political science is poorly positioned to guide its own scholars on the best way to perform field research in countries lacking guarantees for norms of speech, movement and scholarship. This article aims to help address this deficit.

The implications of this lacuna are acute in Southeast Asia, where nine of eleven countries are classified as having authoritarian regimes. The underlying political diversity found within the region makes it a particularly fruitful source of insights drawn from within-country, cross-country or cross-regional analysis (Kuhonta, Slater, \& Vu, 2008). In 
terms of the degree of contestation and participation permitted, present-day Southeast Asia houses politically closed authoritarianism in Thailand, hegemonic authoritarianism in Vietnam and competitive authoritarianism in Malaysia. In terms of institutional arrangements, it simultaneously accommodates a military junta in Thailand, absolute monarchy in Brunei, dominant party in Singapore and personalist dictatorship in Cambodia. For the sake of brevity, we refer to this full range as simply "illiberal" or "authoritarian" in the following discussion. This shorthand need not obscure the real variation in coercion and compliance across the region, which offers a goldmine for field researchers, but also particular challenges. We hope the ethical, logistical and operational recommendations offered here, which are drawn from our own and others' experience, help pave the way for fellow political scientists seeking to work within authoritarian regimes, be they in Southeast Asia or in other regions of the world.

We begin by detailing the difficulties of conducting field research in authoritarian regimes. These hurdles are not exclusive to this setting, but they are acute because of the lack of effective protections for civil liberties and political rights. The resulting practical and ethical challenges for field researchers often require a carefully considered approach as well as specialised information and contacts. Such constraints compound the more universal imperatives of building relationships, sustaining trust, navigating secrecy and working ethically. In some cases, in fact, it may be difficult to separate issues of illiberalism from those of underdevelopment. A lack of reliable public opinion data and accessible archives, for instance, may represent efforts at obfuscation and interference or may stem more from scarce resources, sub-par infrastructure and technological incapacity (Clark, 2006, p. 418; Hertel, Singer, \& Cott, 2009). Drawing on Southeast Asia as a methodological laboratory, we next turn to practical advice for scholars at all career levels on pursuing field research in authoritarian regimes. This includes pre-departure planning, developing a workable strategy, deploying key field-research tools and determining how to present the completed research while maintaining longer-term access. We conclude by addressing the generalisability of our own methodological counsel. Despite the regional focus, our suggestions have practical applications for scholars conducting research in other authoritarian regimes, albeit with due attention to political and cultural context. Ultimately, the methodological challenges of an illiberal context transcend regional boundaries.

\section{Navigating Authoritarianism in the Field}

While the study of political science methods - including, increasingly, field research methods - has made real strides of late, the underlying premise of most of that work is that evidence and insights are out there for the gathering; the hassles are in learning to conduct interviews and observe critically and reflectively, knowing how best to interpret those data, and determining how to organise the logistics of living and working "in the field". We speak more of deploying our social scientific toolbox to collect, rather than to search for, discover or extrapolate the information we seek (e.g. Denzin \& Lincoln, $2008 ; 2011) .{ }^{1}$ In this regard, field research in authoritarian regimes merits specific attention: these regimes themselves tend toward secrecy; nor are their inhabitants likely to enjoy the civil liberties that incline one to speak freely. However necessary research on and in these countries is for our understanding of all sorts of socio-political processes, common tools such as surveys may be impossible or unreliable (not to 
mention beyond the budget of many scholars, regardless), government documents and archives may be inaccessible or incomplete, and the ranks of local social scientists may be limited and/or constrained in their own foci; we may not even know what details or data are available at all, whether qualitative or quantitative, and from whom or where. Scholars new to the field face special hurdles, given the primacy of a well-developed personal network; those connections take time to develop - a fact that also mandates that more senior scholars unable to spend long periods in the field work assiduously to maintain what networks they have, as through periodic check-ins or social media.

The notion that research in comparatively closed settings poses distinct challenges is hardly a revelation. In part, this issue fits within a broader "insider-outsider" debate in ethnography, including, for instance, problematics of research by members of a dominant population vis-à-vis a less advantaged population. Although much of that debate focuses more on questions of voice and representation than the data-collection process per se (e.g. Kobayashi, 1994; Zinn, 1979), issues of access, trust and perspective in the field also loom large, much as they do for research (particularly by non-local scholars) in illiberal contexts. Questions of informants' willingness to play along with the ethnographer's agenda dovetail with these dimensions, even in more democratic, less risk-laden contexts (Newsome, 2014, p. 411).

A separate, but equally challenging, issue is the extent to which field researchers are themselves observed. The most common approach to research ethics, which is institutionalised in university human-subject review board guidelines, focuses on protecting subjects, rather than scholars themselves and those who aid them (Fujii, 2016, p. 1151). The less common approach, which exists in many Australian universities, gives more emphasis to protecting researchers - but sometimes at the expense of their intended research. Particularly in authoritarian regimes, researchers (and their coteries) may themselves be monitored by security or ancillary forces and harassed or otherwise obstructed. Women, members of particular ethnic or religious groups, individuals of non-normative sexuality or gender, or those exploring sensitive topics, among other categories, may face particular risks (West, 2015; Johnson, 2009). Janet Elise Johnson recommends the "good-enough field researcher" as a reasonable objective in such situations, given the impossibility or inadvisability of taking extraordinary risks for the sake of research (Johnson, 2009, pp. 321-322).

Personal safety - for oneself as well as one's interlocutors and intermediaries - is of paramount concern. While contemporary Southeast Asia includes few active conflict zones, hot spots remain and may emerge, and lack of accountability, limited civil liberties, episodic violence and everyday crime (especially where the police lack professionalism) pose real hazards. Sexual harassment, too, is endemic in many field sites. New and established scholars alike are well advised to think through these risks and what they may do to mitigate them: at a minimum, registering with one's embassy or consulate, learning basic self-defence, checking in regularly with a designated contact, scheduling meetings in public areas as much as possible, and arranging appropriate insurance coverage. If one's research may include a live conflict zone and resources permit, a hostile-environments preparedness course, however costly, may be a worthwhile investment; otherwise, consider conferring with locally-based journalists on arrival for current advice, as well as reviewing references on best-practices for journalists or others (for instance, Smyth, 2012; Sriram et al., 2009). 
Meanwhile, the same circumstances that render researchers more likely to be scrutinised also pose daunting challenges for protecting sources and maintaining confidentiality and anonymity, not least where human-subjects guidelines require saving what are potentially damning source materials (West, 2015). Recent debates over a Data Access and Research Transparency (DA-RT) initiative within the discipline highlight the fact that norms of political science research, particularly expectations of transparency and replicability, may be at odds with the need to protect both the researcher and their subjects, when these data have been gleaned from authoritarian states (Shih, 2015). ${ }^{2}$

However known the challenges of field research in authoritarian regimes, discussion of those issues has been more substantial for some regions than others. Scholars of the Middle East and North Africa (MENA) have - at least in recent years - offered usefully introspective discussions of the research process in those states. A July 2006 PS symposium on "Field Research Methods in the Middle East", for instance, noted that political scientists working in the region "must contend with political authoritarianism and violence, anti-Americanism, and presumably deep cultural differences related to religion and, as a result, gender" (Clark, 2006, p. 417). Surveyed for the symposium, scholars of the region reported logistical and ethical dilemmas related to "authoritarian political conditions" as especially problematic, to the extent that political climate affected their choice of countries and methods (Clark, 2006, p. 418). Respondents noted difficulties in areas ranging from acquiring entry and research permits, to securing interviews and convincing interlocutors to trust them and speak freely (leading, for instance, to reliance on snowball sampling ${ }^{3}$ and intermediaries to set up interviews), to harassment by authorities or having had to flee amid political tensions, to seizure of their research data or even being detained themselves (Clark, 2006, pp. 418-419). More broadly, many have difficulty extending their research beyond major urban centres and relatively elite respondents (Haklai, 2009, p. 39). Regardless, after publication, the disciplinary community is apt to treat MENA cases as sui generis rather than as representative of important regime types and variables, and thus to sideline this largely qualitative work from cross-regional, cross-cultural comparison and theory-building (Haklai, 2009, pp. 39-41).

Ethical dilemmas are almost inevitable (and may be exacerbated by geopolitical developments, if the researcher is seen as a representative of the polity from which they hail). MENA scholars, for instance, face complex trade-offs - not unique to the region, but especially stark there - among a "fly-on-the-wall" model of dispassionate observation; a "reciprocity model" of using one's greater resources and access to offer in-kind or moral support to local communities; an "activist model" of taking a principled stand against abuses and advocating change within the society they research; and of using their expertise either to assist their home government's policymakers, or to oppose those home-state policies with which they disagree (Carapico, 2006). Regardless, the usual difficulties of coaxing cooperation with one's research efforts (cf. Chambers, 2014, on the hassles and costs of collecting data in the field) invariably also apply.

Some of the anti-Americanism, for instance, that trips up US-based researchers in the Middle East is less (or less consistently) relevant to regions such as Southeast Asia; however, suspicion of scholars' motives or agendas remains salient. ${ }^{4}$ That suspicion may come from state actors, but is just as likely from non-elite persons who worry about the reputational or material risks they may encounter by engaging with foreign 
researchers. Particularly for those researching fraught political questions in dicey political contexts, sustained, serious reflexivity - awareness of the place of oneself as researcher, the power dynamics and privilege in play, and the relationships in which both researcher and interlocutors are embedded (Fujii, 2016, pp. 1150-1151) - is essential. Such considerations highlight the variations among regimes: receptivity to foreign and domestic researchers alike tends to be higher in hybrid than single-party states in Southeast Asia, for instance, but also varies with the political questions at issue, the current balance of diplomatic relations, and the state's capacity or will to monitor research under way or control local academic institutions and endeavours.

In some ways, recommendations extrapolated from one authoritarian setting apply well to others; while we draw from our own experience in Southeast Asia, we anticipate that much of what we say will ring true for scholars of other regions. (We return to this question in our conclusion, below.) In other ways, as the very nature of field research affirms: norms and local histories of field research (and of Euro-American involvement) vary, local academic communities (and the relative prevalence of locally-based or diasporic researchers among those present) vary, relevant dimensions of authoritarianism or hybridity vary, and the specific risks facing dissidents, including nosy foreign researchers, vary. Perhaps because rumination on methods tends to be strongest in American political science, and a paltry proportion within this category focus on Southeast Asia (let alone specifically field-based research strategies in the region), attention to the vagaries of fieldwork in the region lags. A recent survey of US-based political scientists' field research projects yielded a top-40 list of research sites that included not a single country in Southeast Asia (Kapiszewski, Maclean, \& Read, 2015, p. 55). In Australia, a survey of graduate students in political science found that 60.4 per cent believed they had not received enough methods training, let alone training in how to conduct field research (Kefford \& Morgenbesser, 2013). This knowledge deficit represents both a challenge and an opportunity.

A number of recent initiatives nevertheless suggest a trend. The most obvious is the interdisciplinary edited volume, Methodology and Research Practice in Southeast Asian Studies (Huotari, Rüland, \& Schlehe, 2014), which homes in on tools and types of research and analysis, including the intersection of Southeast Asian studies with various disciplines. A recent symposium in APSA-CD examines the nuts-and-bolts of field research methods, with contributions by and for graduate students and early-career scholars of the region (Weiss, Hicken, \& Kuhonta, 2017). Together they follow a ready chorus of spirited defences of area studies and qualitative research broadly. The most prominent are Southeast Asia in Political Science: Theory, Region, and Qualitative Analysis (Kuhonta, Slater, \& Vu, 2008) and a special issue of Pacific Affairs on the comparative study of Southeast Asia (Huotari \& Rüland, 2014). ${ }^{5}$ None of this scholarship, however, focuses substantially on the peculiar vagaries of research in authoritarian regimes, notwithstanding the mix of subtypes found in the region. It is to that niche that we now turn.

\section{Planning for the Field}

Much of the hard work of field research is best conducted before one leaves home: adequate preparation vastly increases chances of success, even if rarely precisely in the form expected. Graduate students and early-career researchers should start by speaking 
with not only advisors, classmates and colleagues, but also political scientists who have conducted research in your target country. In addition to learning what to expect, you should determine what your legal rights are as a (foreign) scholar and the nature of the risks you face should someone in a position of authority take issue with your presence. Determine early on what sort of research permit you will require - more on this issue below - and how long the application process may take. Ideally, start at least a year in advance (as the authors have had it take that long).

Be mindful of the ethical conundrums or uncomfortable circumstances you may face once in the field. It is easier to plan a response in advance, in a calm environment, than on the fly, under pressure. These challenges extend well beyond straightforward questions of whether your intervention will "do harm" - all scholars must carefully consider what ethical principles, cultural sensitivities or risks are at stake in relation to their research questions (Mollet, 2011). They may appear both during and after field research. A few common examples include interviewees who request favours or make unwelcome advances (especially in the case of female researchers), vulnerable interlocutors who want to have their stories told and discount your concerns about their safety, and citing interviews such that respondents are genuinely unidentifiable (Clark, 2006, pp. 420-421). If, like most political scientists, you lack formal training in fieldwork methods, practise using your primary tools before you depart. In Australia, for example, reaching out to the local associations representing Southeast Asia's diaspora communities is a cost-effective way for graduate students to practise interviewing and likely generate contacts within the targeted country. The same holds true for interviewing an expert over Skype and spending time in a local archive.

Once you have a sense of the lie of the land, the first step in organising field research - whatever the context - is determining what you need to find and how and where to find it. Adequate preparation is essential, including making backup plans in case things go awry. We recommend starting by contacting local journalists, academics, activists or pundits (including retired politicians) before you arrive; these individuals may be easy to track down and well-placed to give you the lie of the land, general tips and initial contacts. We also recommend graduate students sign up on Twitter and "follow" the above sources well ahead of their planned field research. (Social media usage is high in much of the region and rising throughout it.) Engaging with these individuals on a regular (and friendly) basis in such ways may allow them to become your first port of call once in country. All scholars should develop a map of who is who, highlighting whom you most need to meet, where they fit in your analysis, what contact information you hold, and who might be able to connect you. The elusiveness of one's research targets may be intrinsic to the case at hand. Barros (2016), for example, notes the methodological hurdles of studying interactions among authoritarian elites, given the secrecy with which they tend to operate and how imperfect "public artifacts" such as policies or official pronouncements are as indicators of autocratic workings. This obstacle can be overcome, but it requires careful and detailed planning.

Simply identifying relevant sources and gaining access to them is a core challenge in countries that offer no assurances or even norms of transparency. What happens if, despite your best efforts, you find it impossible to proceed as planned? While some decisions cannot help but be made in situ (see the next section), advance strategising remains worthwhile. Since Southeast Asia's authoritarian regimes vary greatly in the extent and 
nature of their censorship or control of online information (cf. Greitens, 2012), determine what materials are available through your home library or online so you do not lose valuable time in the field pursuing those materials. We recommend a data-collection plan such as sketched in Kapiszewski et al. (2015, pp. 89-95) or at a more functional minimum, a spreadsheet indicating items needed (files, pieces of information, statistics etc.), where each is located, and, perhaps most importantly, whether you have already acquired it. (However obvious that last point may seem, it is almost inevitable that, at least once, you will go to great lengths to find the same item twice.)

Use your research to-do list as a starting point for determining where to affiliate and in what guise. Not only may your funder require a local affiliation, but having a "home base" in a university political science department or an independent think tank may facilitate your research process. Being a "visiting fellow" or "visiting scholar" may provide an institutional bulwark against interference and intimidation from political authorities, especially if you plan to stay a while. Indeed, however tenuous that regime's commitment to university autonomy, it may still fear bad press or elite blowback if it meddles with research within a local institution. Another key benefit of affiliation is the umbrella of credibility it provides in terms of accessing archives, interviewees and other research participants. Public officials may require a letter on official letterhead, for instance, before agreeing to meet (though you may find yourself pressed to temper your line of inquiry if you present yourself as a representative or employee of that local institution). Finally, having a desk, library, reliable internet access and community of scholars with whom to check in can be a huge help, particularly if your budget precludes a well-equipped living environment.

Sometimes your choice of affiliation is essentially premade: your university has an agreement with a local research centre, your funding is from an agency with a local office, or you are collaborating with a particular university-based academic. Assuming the choice is yours, though, consider what institution (university, research institute or non-government organisation) will grant you the easiest or widest access to published materials, archives or people you need to find for your research. An equally important consideration, especially if your research is on a sensitive subject or you expect research clearance to be difficult: will certain forms of affiliation, or collaborating with a particular institution, make it easier for you to be there legally? Before going into the field, learn where scholars in your area have previously based themselves and, if necessary, enquire into how they managed to organise their stay and what their experience was. In Southeast Asia, for instance, some possibilities include the ISEASYusof Ishak Institute in Singapore, Yangon School of Political Science in Myanmar, and the Thai Development Research Institute. All three have track records of hosting foreign researchers. Graduate students should expect to come with their own funds, but not being paid will allow you greater flexibility and freedom to pursue your own research agenda, even if you are expected to produce an article or present a seminar for your host institution.

Most countries in Southeast Asia require that all foreign researchers obtain a research visa or permit - determine what sort you will need and what sort of documentation its acquisition requires. The question of whether the "correct" visa needs to be secured depends on the specific nature of the research. The options available to graduate students, 
especially those conducting lengthy field research stays, might be restricted by grant or home-institution rules. We advise that students ask fellow or recent graduate students how best to approach the visa-application process and, especially, how to frame research plans to increase the odds of approval; more senior scholars might not have gone through that process in a long while and the process may shift slightly even just with personnel changes. Simple adjustments in wording, including avoiding red flags like "authoritarian", may placate sensitive bureaucratic officials. This kind of subtle alternative has proved to be effective in securing research visas throughout Southeast Asia.

Organisational affiliations may require institutional and/or government approval of your research agenda. Some national archives and other information sources may require separate clearance, including ad hoc assessments of the researcher's motives and biases. (More on these issues below.) Even in authoritarian regimes with relatively greater protection of civil liberties and political rights (that is, a place like Malaysia rather than Vietnam), coming prepared with both a cover story - most likely a plausible and not fallacious, but non-sensitive spin on why one is there - and clear documentation of one's status and affiliation(s) helps. If you have a professional website, for example, make sure there is nothing on it that is likely to cause you undue hassles. One author, for instance, was nearly denied a (non-research) visa to Myanmar early in the country's transition process: the consular official in charge in Washington, DC had printed out her university webpage and highlighted certain works on the region, explaining that he was uncomfortable allowing a political scientist with such interests into his country so close to an important election. Only the intercession of a well-connected friend resolved the issue.

Beyond arranging your formal affiliation (and assembling a cache of small-scale swag from your university to dispense as token gifts - university pens are useful and highly portable), check with your aforementioned local experts before you head off to the field. Will the institute with which you are considering affiliating entail any reputational costs among your intended informants? Is it better to carry business cards from your home university or that local host? ${ }^{6}$ Are there any upcoming disruptions - elections, holidays, religious festivals, sporting events - you might not have considered, but that should factor into your plans? If you know you will need to access local archives or libraries, find someone who has used those repositories before and request advice or contacts one helpful archivist can make your job much easier. If a particular journalist, for instance, seems interested in your work, see if she might consider letting you tag along when she covers an event shortly after you arrive. While press freedom is in short supply across Southeast Asia, you may still feel more comfortable and attract less notice starting your observations under cover of media than independently.

\section{Working in the Field}

Our focus here is on how to conduct archival research, interviews and participant observation within the distinctive environment of Southeast Asia's authoritarian regimes. Given that a fuller explanation of these methodological tools is beyond the scope of this article (and already available elsewhere), we seek to provide a general framework for applying them in this setting. ${ }^{7}$

The importance of time, creativity, patience and tenacity is a common theme that runs through the discussion of research modalities. All the steps we detail require some 
combination of building a network, trying multiple angles and being as prepared as possible. All at least benefit from, if not require, an extended stay in your research site. Besides posing a potential risk in itself, this requirement puts a premium on your being financially viable and organisationally proficient. It recommends that a prospective field researcher arrive with their homework complete: who is in country who might be of help, what work has already been done, and where to go for information and moral support if (when) surmounting an authoritarian regime's obstacles becomes too frustrating.

\section{Archives}

Accessing materials from archives is a core task for qualitative political scientists. The data typically sought includes correspondence and communiqués, court records, diaries, minutes from intra- and inter-governmental meetings, official reports, parliamentary proceedings, speeches, statistics, travel logs, and so forth. Finding such materials in and on Southeast Asia's authoritarian regimes, however, may require overcoming significant, and not always predictable, obstacles. We exclude from this discussion more clearly catalogued and readily accessible materials held in archives in France, the Netherlands or the United Kingdom, since the field research experience to access those materials is likely to be more straightforward - with the caveat that one might do well to check there, too, especially for colonial-era and early-postcolonial records. Online archives, including WikiLeaks, may also be helpful, although they are likely to be at least as easy to access from home as from the field (see Michael, 2015).

There is no correlation between authoritarian regime type and relative accessibility of archives. In our experience, Cambodia, Singapore and Thailand offer the least troublesome national repositories for research, while Malaysia, Myanmar and Vietnam routinely frustrate scholars through some combination of oblique application procedures, excessive questioning, and local-affiliation requirements. (For tips on using archives in Cambodia, Myanmar and Vietnam, see Kim, 2017). Attaching oneself to a local university or research institution may help to overcome these obstacles, especially if a staff identification card conveys access rights not available to independent researchers. Graduate students might want to offer to write a "blog post" for a local political science department or research institution in exchange for securing their affiliation. Other options may include securing a letter of recommendation from your local consulate/embassy; paying the archive staff for access (not always an option); submitting an application to investigate a cognate but less sensitive research topic if you anticipate resistance; or, resources permitting, recruiting a local researcher to carry out the data collection - with the caveat that you may not know what is there, so likely will not be able to send your assistant in with a straightforward shopping list. The authors have used all these tactics (including as graduate students) when researching issues such as elections, democracy, human rights, protest movements and student activism.

On the other hand, the opacity and secrecy of authoritarian regimes means certain types of sources are either destroyed rather than saved or never recorded (for instance, records of proscribed organisations), not stored in public archives, or simply not accessible to researchers. Typically, for the most sensitive documents to become publicly available requires political liberalisation and enactment of freedom of information 
laws. These documents might include those pertaining to corruption, political parties and elections, elite rivalries, human rights violations, and the military. For instance, democratisation in Indonesia has brought long-suppressed documents to light. Just one example: in the course of her dissertation research, Melvin (2018) discovered a trove of never-before-studied official files that meticulously detailed the Indonesian military's orchestration of genocide in Aceh in 1965-66.

Such notable examples aside, though, most authoritarian regimes are adept at either not keeping, or securely concealing, records of the very events, issues and proceedings that are most relevant to political scientists. Two distinct, complementary responses may help to mitigate. One approach is to try to gain access to the private archives of former government officials, party members or security personnel. For instance, journalist William Rempel (1993) was able to gain exclusive access to 2,500 handwritten pages from the secret diaries of Ferdinand Marcos; from that resource, he recounted the latter's quest for a place in history alongside his models, Julius Caesar, Napoleon and Hitler. This strategy is a difficult one on which to rely; it depends on a sophisticated network of contacts or requires a good deal of luck - or, as in Rempel's case, the collapse of the authoritarian regime in question. Another way to compensate for the lack of archival source materials is to utilise other qualitative tools, such as interviews and participant observation. The modern states of Southeast Asia are still comparatively young; much of at least postcolonial political history is still within memory of people who can be interviewed. We have had success, for instance, in supplementing scarce documentation on since-suppressed left-wing parties with interviews with former party members.

Despite the fact that scholars - especially graduate students - might feel constrained by their existing data collection plan, flexibility and iteration are fundamental to good fieldwork (Kapiszewski, Maclean, \& Read, 2015, p. 94). This imperative is especially the case for political scientists working in authoritarian regimes, where the limitations of field research are more disabling. Lack of access to materials - or the unavailability of documentation at all - requires creativity, triangulation, and above all, patience.

\section{Interviews}

Much the same obstacles that apply in accessing archives also apply to conducting nonelite interviews; elite respondents may be hard to pin down for interviews and/or evasive in their responses, but their caginess is less likely to reflect endemic vulnerability. The very nature of authoritarian rule means civilians may be apprehensive about talking to foreign researchers, unwilling to disclose their grievances openly, and in some cases, accompanied by a "minder" or concerned they are being watched. Using local networks and resources is critical.

We recommend thinking in terms of building a formal or informal team to help you navigate the authoritarian landscape: people who can not only provide you with contacts, but vouch for you as you work to build trust with your interlocutors. To build that team, start by asking more experienced peers, journalists and aid workers, as well as sympathetic researchers in local universities or research institutions: explain the sort of people you need to meet and ask their assistance in making those connections. The value of these "associates", "brokers", "middlemen" or "fixers" - a category we 
distinguish from local co-researchers with more than a facilitating role - is that as trusted intermediaries, they help to close the gap between you and your respondents and curtail suspicions about your motives or trustworthiness. In Laos, Vietnam and Thailand, for example, interviewing members of rural households may be enabled by an initial introduction to the village chief; an intermediary may help you work through the established hierarchy, in the process expanding the pool of interviewees you might reach. A key factor in building this team may be logistical: whereas established, salaried, grant-endowed researchers may be able to afford to hire local assistants, scholars earlier in their career, and especially graduate students, are more likely to lack such resources. We stress that your team need not include paid research assistants, but might be a more informal, hopefully mutually beneficial, collection of advisors and people with interests, expertise or access distinct from your own. Think carefully about how to "give back" to and collaborate with this network. Beyond a pro-forma dissemination-of-findings aspect, you could co-author a journal article with an academic intermediary (since academics across the region are increasingly pushed to publish in indexed, Englishmedium journals, regardless of linguistic facility), offer feedback on a local colleague's own research plans, advise a local colleague on options for study overseas, or summarise relevant aspects of your findings for a local NGO newsletter.

Before starting your interviews, however, determine how you will document them, then how you will protect the identity of your respondents and secure your notes or recordings. While recording interviews allows verbatim quotation and more reliable accuracy than note-taking, where individuals are worried about surveillance or simply unused to speaking freely, especially with a foreign researcher, they may be put off by a recorder. We have found the greater candour that not recording may encourage to be often worth the trade-off in detail, from not having a verbatim transcript - and strongly advise bringing comfortable pens and plenty of paper, and practising shorthand or other speed-writing techniques. ${ }^{8}$ As for ensuring anonymity of those notes: so long as the specific position of the individual is not important more likely the case for non-elite than elite interviews - a simple solution is to avoid potential identifiers by using a two-step anonymity process. Instead of specifying a particular person (Muhammad Shah) and precise location of the interview (Gadong, Bandar Seri Begawan, Brunei), scholars can use a generic or coded title - anything from "Citizen 1", if the position of that individual is not salient to how you will cite them, to a label that reflects where they fit in your analytical framework - and inexact location (Bandar Seri Begawan, Brunei). In addition, we recommend the use of widely available data encryption tools to protect any digital recordings and typedup notes or transcripts. Be aware that having to sign a printed consent form, however well-intentioned to protect one's human subjects, may be alarming especially for non-elite interlocutors in an authoritarian setting. Instead we recommend securing your human-subjects review board's permission to use oral consent. If you use an interpreter, be alert, too, to their relative visibility - and bear in mind that your interlocutors might worry that your interpreter could be a regime informant.

Elite and non-elite interviews require tailored strategies for securing meetings as well as framing and targeting questions. Conducting elite interviews in authoritarian regimes presents unique challenges, regardless of the researcher's career status. For one thing, except in Singapore, it may be impossible to plan ahead: in most of the 
region, the norm (at times encouraged by cultural practices or technical barriers) is that political elites prefer to schedule meetings on short notice, often using informal tools such as text-messaging to communicate rather than more formal approaches. ${ }^{9}$ If your research requires extensive elite interviews - and especially if you lack an established reputation in that research site that might spur accommodating responses - you may have no choice but to plan a longer visit, rather than one or more brief visits, to accommodate unpredictable schedules.

Access to these individuals, as well as what you might expect them to offer, is conditioned by the nature of authoritarian rule: they face scant incentives to demonstrate accountability, foster transparency, or provide trustworthy information on topics of concern. In some cases, too, political elites might be fearful for their own safety, should they say too much - particularly those in the opposition. Triangulation is essential, including doing sufficient preparation that you can (politely) call a bluff when appropriate, or at least press further when you are aware you are being given a partial or skewed account.

In our experience, gaining access to political elites in authoritarian regimes depends to a significant extent on interpersonal connections and relationships. Cold-calling or sending unsolicited emails is a less effective method - though it is worth trying, if your only option. In Myanmar, for example, as a graduate student, one author walked straight up to the headquarters of the National Unity Party, which had competed in the 1990 election on behalf of the ruling junta. This approach yielded interviews with a range of senior party officials. Beyond cold-calling, networking matters. For both elite and non-elite interviews, work your way toward harder-to-get interview targets through referrals along the chain. In Malaysia or Singapore, for instance, a personal introduction from an intermediary to a ruling-party politician may be the only way to secure an interview - or at least, one that goes beyond pat talking-points; if that interview goes well, this first respondent may offer their colleagues' contact information and allow you to drop their name when you make those calls. That intermediary could be (and has been, in our own experience) a personal friend who is a constituent or relative of a target legislator, a colleague from a local university, a journalist, a local book publisher or a former school-mate of someone you would like to meet. In Cambodia, we have found it helps to work with several locally-based associates: on one occasion, for instance, with three intermediaries who had previously helped local political science colleagues arrange interviews with high-ranking officials from the Cambodian People's Party. Such assistance was only forthcoming because the author - a graduate student at the time - had established a level of peer-to-peer trust well before travelling to Cambodia (see previous section).

Beyond the use of intermediaries to secure individual interviews, you may have the good fortune of identifying - or often, stumbling across - a gatekeeper. This individual can facilitate access to a pool of potential participants (King \& Horrocks, 2016, p. 31), whether by virtue of their formal role or their informal authority. Gatekeepers in authoritarian regimes may include a political party chair, the chief of a security force, the director of a branch of the civil service, the speaker of parliament, and so forth, as well as less obvious individuals who wield substantial non-institutional power, such as publishers or even socialites. Each of these individuals commands some degree of authority over a large group of people; if you succeed in reassuring them of your 
credibility and trustworthiness, they may agree to grant you access, leveraging their own network of interpersonal connections and relationships. In Malaysia, for example, one author was able to interview several current and former ruling-coalition members of parliament by first having a successful discussion with a well-respected former cabinet member; that individual effectively served as a gatekeeper, allowing the author to use his name when calling any of a list of people in his "camp". Likewise in Myanmar, one author was able to conduct interviews with political elites at the highest echelons of the bureaucracy, government and ruling party by meeting with the owner of a transportation company. The owner turned out to be a personal friend of President Thein Sein, who "opened the gate" to a large pool of very coveted respondents. This example in particular demonstrates that luck helps when it comes to procuring interviews in authoritarian regimes, but also that a diligent political scientist leaves no stone unturned.

\section{Participant Observation}

We leave perhaps the trickiest strategy for last. Participant observation or ethnography what Kapiszewski et al. (2015, chapter 7) call "site-intensive methods" - spans a wide range of tactics in political science research, from observing protests, to shadowing politicians, to embedding oneself in a village or factory. All these forms are made more risky where one is an obvious outsider (as non-Asian researchers will likely appear immediately to be, anywhere in Southeast Asia), and where freedoms of assembly and speech are curbed. We have ourselves gained critical insights through participant observation; we are not suggesting that one need eschew these methods outside liberal democracies. But we do strongly advise that before embarking on such research, you work through the implications and risks involved - not just for you, but for those around you. For instance, you might want to volunteer with a local non-government organisation, to get a better sense of the workings of civil society and to make contacts. Perhaps seek a behind-the-scenes role: offer to edit a newsletter or rearrange a library, out of the public eye. You will not be doing the organisation any favours if your presence leaves them open to charges of being a tool of "Western" interests. If your target is a demonstration or election rally, consider positioning yourself near the media (especially if foreign media are present), for the same reason: you will be visible, but can minimise how obvious you are.

As both of these suggestions imply, particularly where political participation is curbed for all, and especially where it is verboten for non-citizens, we advise emphasising observation rather than participation per se, however much your own presence is always a factor. Above all, respect those you are studying: they are citizens and vulnerable, not specimens. If they ask you not to attend an event, or to stay well in the background, know that you may compromise not only your own reception, but also their safety and the event's success, should you disregard that request. By the same token, keep your own security in mind. If travelling alone to a night-time event, or attending a rally that you suspect might turn violent, take reasonable precautions - or err on the side of safety, rather than pressing for that one additional datum or story. 


\section{Returning from the Field}

With your field research complete, you will face two core fieldwork-related tasks: analysing your data and writing up your findings, and ensuring that you may still return to that field site in future, should you wish to do so.

Your first step, if you have not already finished doing so in the field, should be typing up any remaining interview notes, field notes or other documentation. Really, this task is best completed as soon after the fact as possible, before nuances and details slip from your mind - including details on the location, what was happening around you etc., to jog your memory (Hertel, Singer, \& Cott, 2009, p. 307). Cross-check your data collection plan or spreadsheet to see what remains to be collected - there will always be something - then set a timeline for polishing up your data collection, making sense of what you have, and writing up your findings.

It is beyond our scope to get deeply into the methodology of data reconciliation and analysis. Several excellent works on qualitative analysis (for instance, the ten works reviewed in Elman, 2008) offer insight into working with interview and observation data, documents of various sorts, and other materials, along with broader issues of epistemology, explanatory frameworks and theoretical interventions. Most germane for our purposes are narrowly gauged questions of how to anonymise and obfuscate, to protect your human sources and connections, while maintaining credibility; it is on these areas that we focus.

Above, we addressed securing your data while in the field. Now comes the perhaps equally dicey stage of drawing on qualitative research with enough detail to be credible, but not enough to get anyone into trouble. Here the norms of the discipline may run afoul of the reality of the field. We prefer to ask respondents how they prefer to be cited, always with the offer of anonymity or non-attribution. We have, though, then faced the dilemma of activists' requesting that we use their names, when we have reason to believe doing so is not in those respondents' best interests. Particularly when these respondents are still comparatively young and early in their careers, and not already prominent figures, we have disregarded their requests, erring on the side of disrespect rather than damage. (Barter, 2017, notes much the same issue for his work in conflict zones in the region.) Anonymising through describing the position of, rather than naming, respondents may be adequate - though if a respondent is, say, the leader of an opposition party, the range of possibilities who fit that description will be narrow. (Make sure your strategy for obfuscating identity, noted above, leaves you access to the details you need on the respondents you cite.) In general, we recommend a broad brush for such labels: "an opposition activist", "a town in northern Thailand" etc. The onus is then on you as author, however, to interpret reasonably and represent accurately these essentially uncheckable details. A combination of government secrecy and thin scholarship mean interview and observational data may be essential to building an argument; those hardwon appointments are not merely for the sake of finding the occasional zinger or illustrative quote, or for backup examples tucked away in footnotes. At a minimum, interview material should be reconciled via a process of triangulation - a research procedure that employs empirical evidence derived from multiple sources to strengthen the validity of both descriptive and causal inferences (Yin, 2003, pp. 97-101). 
The next challenge is to be able to continue your research, particularly for those just embarking on their academic careers and often with a substantial investment in language study. Of course, being banned may still have a happy ending: several of the most renowned Southeast Asianists have had to shift their attention to another country due to either their own banishment from, or crackdowns on research generally in their initial or intended country of focus - perhaps most famously, Benedict Anderson, who continued his illustrious career elsewhere in the region once unable to work in Indonesia. All the same, most of us would rather have the option of continuing, so we do need to navigate the minefield of writing with integrity and getting our work noticed enough to advance our careers, while not attracting unwanted interest from state actors. That challenge is all the more keen when one does have a normative objective in mind: when activism and scholarship intertwine. The advisor of one of us once recommended - when asked for input regarding an invitation to present portions of dissertation research for a US security agency - to accept, but not to temper the presentation in hopes of a second invitation. For those circumstances, that advice was spot-on (and indeed, the invitation was not repeated). The matter is more dubious, though, when the audience is the government one is studying - in this case, the US government was neither the focus of study nor even a hoped-for employer. So, how best to publish and disseminate one's research, and to ensure it is widely accessible, when doing so might compromise one's future access?

Some scholars are willing and even eager to take on the state they study: their goals are not merely analytical, but also activist. Others see their role more as outside observers, even if they do have normative commitments vis-à-vis the regime in question, and perhaps engage in low-level and/or home-country efforts in light of these commitments. While we respect both these approaches, we focus here on the latter since it is this segment that will presumably be less willing to accept the risk of being shut out of their research site for speaking their mind.

Some steps are simple, but might be uncomfortable or contravene more careeroriented goals. The first recommendation is simply to lie low. As a foreign (or foreignbased) scholar, you may find plentiful opportunities to be a media darling in the region, whether via in-country television programs, local independent or online platforms, academic blogs, or any number of public forums covered by the press. The more visible you are, the more likely you will be noticed, perhaps be adjudged as partisan (which might make it difficult to obtain interviews or information from some quarters in future), and be scrutinised. Keeping a low profile might be frustrating - who does not enjoy the chance to pontificate on occasion? - and means even those likely to be sympathetic to your perspectives are less likely to know of you when you seek them out, but it also makes you less apt to be prevented from entering or assumed to be biased or meddling. By the same token, if important people ask for a copy of your dissertation or publication, "forgetting" to send it could be wise. (Chances are, they will not read it, regardless, but there is no need to stir the pot.) That said, for many of your interlocutors, simply sharing the results of your research - sending off copies of your dissertation, books or articles you produce - may be an easy way not only to maintain contact, but to keep you honest, by inviting your respondents to review how you represented them in what you wrote. And if you are writing on issues or episodes marginalised from textbooks and public discussion, making your work available locally, 
in however low-key or selective a way, might usefully redress an authoritarian information blockade.

Indeed, part of preparing the way for a future career is maintaining contacts: the trust built on one visit need not be redeveloped from scratch, but will hopefully cumulate. We have found that some of our best contacts for securing interviews are simply long-time friends in the countries in which we work; as they and we grow older, and as our research foci shift, the odds increase that one of them will happen to know someone we might really like to interview, and be willing to broker a meeting. (This process need not be so opportunistic in practice as it reads!) As detailed above, where trust is essential, personal connections are key - those starting out are at an inherent disadvantage, but usually just a temporary one.

\section{Conclusion}

We might conclude by returning to the question of how widely these ideas and prescriptions extend: is what applies to Southeast Asia's illiberal states generalisable to all authoritarian contexts? The answer revolves around the nature of authoritarianism - or more accurately, of the illiberal state. By definition, the illiberal state intrudes into society, including, generally, academia. For that reason alone, we might expect what we find applies across authoritarian Southeast Asia to apply to field research in authoritarian states elsewhere: illiberalism, including curbs on civil liberties and academic freedom, contorts the research process, often in fairly predictable ways. Moreover, some aspects may apply even to purported democracies, where academic freedom - including the space for research and critical inquiry - is constrained. (For instance, Brand (2007) finds limitations on academic freedom run the gamut of states in the Middle East and North Africa, as well as obstructing specialists on the region based in the United States and elsewhere.) Part of what makes attention to the basics of field research in these difficult settings so important is that, however challenging the research may be to visiting Western academics, the hurdles are all the higher, and the risks very much greater, for local scholars.

The authoritarian regimes in which we have ourselves conducted research span the illiberal spectrum: Malaysia is far closer to democracy, in terms of regime attributes, than Laos, for instance. And yet the states in our sample with the most plausibly meaningful, if still stunted, elections are also the ones with the strongest state capacity - and hence, the greatest ability to patrol the boundaries of academia and civil society (as well as having reasonably easy access to English-language academic publications). Importantly, though, in none of these Southeast Asian states is the military currently the ultimate enforcer it is in many other authoritarian contexts; levels of political violence and intimidation tend to be correspondingly lower, as well, however coercive the state may still be. Neither local nor foreign academics worry seriously about the sort of brutality on campus, or the targeting of students and academic staff, that is to be found in contemporary Iraq, for instance (Brand, 2007, p. 386) - although they might have, in prior periods in Indonesia and Myanmar. Regardless, while foreign academics have the ability and usually the intention to leave after their research, then publish and work in their home country or elsewhere, they still experience limits on academic freedom in the course of their field research. ${ }^{10}$ The relative closure of the local academic environment matters: is 
there a local community of social scientists, is there support for critical inquiry into the workings of the political order, are there local collaborators with whom to work, are local scholars able to write on politics, themselves? As scholars, however much we may focus on our own careers, we must be - and cannot avoid being - alert to the larger academic milieu.

\section{Notes}

1. The epistemological stance of most such work is also firmly positivist (see Fujii, 2016, p. 1149 on Kapiszewski, Maclean, \& Read, 2015).

2. DA-RT guidelines do allow authors to invoke confidentiality at the time of submission, but leave it to journal editors to decide whether or not to proceed with manuscript review by granting an exemption from transparency rules (DA-RT, 2014). Among other critiques, qualitative researchers have argued that DA-RT is inappropriate to non-quantitative data, ethically problematic and a misguided approach (see Isaac, 2015; Cramer, 2015, and other contributors to that symposium).

3. Despite its being maligned as likely to generate a skewed sample, Cohen and Arieli (2011) endorse snowball sampling as being well-suited to gaining trust and securing cooperation among marginalised or beleaguered populations. This logic applies equally to conflict environments and authoritarian regimes, which present similar risks to informants and challenges for researchers.

4. One author used to be asked fairly frequently in Malaysia and Singapore whether they were connected with the Central Intelligence Agency (or was simply assumed to be so). They were not.

5. For a cognate argument on Middle East studies, noting many of the same issues of centrality of field research and balance between empirical specificity and disciplinary extensibility, see Haklai (2009). For a defence of ethnography and interpretive analysis as a basis for theoretical engagement, see Wedeen (2010).

6. A card from an elite Western institution may carry more status locally and help win you access, while a card from a local institution may offer a level of validation and legitimacy (quite apart from your visa status).

7. See, for example, Gillespie and Michelson (2011) on participant observation; Leech (2002) on interviews; as well as Morgan (1996) and Kapiszewski, Maclean, \& Read (2015) on focus groups.

8. On the advantages and disadvantages of recording participants, see Hertel, Singer, \& Cott (2009, pp. 306-307).

9. The same has been found to apply in Russia and China (Rivera, Kozyreva, \& Sarovskii, 2002; Solinger, 2006).

10. The contrast with US-based scholars of the MENA region is striking. Since 2001, there has been a tightening of what was already "a significantly circumscribed framework of expression". This constriction is particularly acute in relation to the foci, approaches and dissemination of research (Brand, 2007, pp. 388-389).

\section{Acknowledgments}

The authors wish to thank the editorial team and anonymous reviewers for their valuable comments. 


\section{Funding}

Financial support for this research project was provided by the Griffith Asia Institute (Griffith University).

\section{ORCID}

Lee Morgenbesser (D) http://orcid.org/0000-0002-3062-1284

\section{References}

Barros, R. (2016). On the outside looking in: Secrecy and the study of authoritarian regimes. Social Science Quarterly, 97(4), 953-973.

Barter, S. (2017). Dangerous fieldwork in Southeast Asia. APSA-CD, 3(1).

Brand, L. (2007). Middle East Studies and academic freedom: Challenges at home and abroad. International Studies Perspectives, 8(4), 384-395.

Carapico, S. (2006). No easy answers: The ethics of field research in the Arab world. PS: Political Science and Politics, 39(3), 429-431.

Chambers, C. (2014). Data collection, opportunity costs, and problem solving: Lessons from field research on teachers' unions in Latin America. PS: Political Science and Politics, 47(2), 405-409.

Clark, J. (2006). Field research methods in the Middle East. PS: Political Science and Politics, 39(3), 417-424.

Cohen, N., \& Arieli, T. (2011). Field research in conflict environments: Methodological challenges and snowball sampling. Journal of Peace Research, 48(4), 423-435.

Cramer, K. (2015). Transparent explanations, yes. Public transcripts and fieldnotes, no: Ethnographic research on public opinion. Qualitative \& Multi-Method Research, 13(1), 17-20.

DA-RT. (2014). The Journal Editors' Transparency Statement (JETS). Retrieved from https:// www.dartstatement.org/2014-journal-editors-statement-jets

Denzin, N., \& Lincoln, Y. (Eds). (2008). Collecting and interpreting qualitative materials. Los Angeles: Sage Publications.

Denzin, N., \& Lincoln, Y. (Eds). (2011). The SAGE handbook of qualitative research. Los Angeles: Sage Publications.

Elman, C. (2008). Symposium on qualitative research methods in political science. Journal of Politics, 70(1), 272-292.

Feldman, M., Bell, J., \& Berger, M. (2003). Gaining access: A practical and theoretical guide for qualitative researchers. Walnut Creek: AltaMira.

Fujii, L. (2016). Politics of the "field". Perspectives on Politics, 14(4), 1147-1152.

Gillespie, A., \& Michelson, M. (2011). Participant observation and the political scientist: Possibilities, priorities, and practicalities. PS: Political Science and Politics, 44(2), 261-265.

Greitens, S. (2012). Authoritarianism online: What can we learn from Internet data in nondemocracies? PS: Political Science and Politics, 46(2), 262-270.

Haklai, O. (2009). Authoritarianism and Islamic movements in the Middle East: Research and theory-building in the twenty-first century. International Studies Review, 11(1), 27-45.

Hertel, S., Singer, M., \& Cott, D. (2009). Field research in developing countries: Hitting the road running. PS: Political Science and Politics, 42(2), 305-309.

Huotari, M., Rüland, J., \& Schlehe, J. (Eds). (2014). Methodology and research practice in Southeast Asian Studies. New York: Palgrave Macmillan.

Huotari, M., \& Rüland, J. (2014). Context, concepts and comparison in Southeast Asian Studies. Pacific Affairs, 87(3), 415-439.

Isaac, J. (2015). For a more public political science. Perspectives on Politics, 13(2), 269-283.

Johnson, J. (2009). Unwilling participant observation among Russian Siloviki and the good-enough field researcher. PS: Political Science and Politics, 42(2), 321-324. 
Kapiszewski, D., Maclean, L., \& Read, B. (2015). Field research in political science: Practices and principles. Cambridge: Cambridge University Press.

Kefford, G., \& Morgenbesser, L. (2013). Bridging the information gap: A survey of politics and international relations $\mathrm{PhD}$ students in Australia. Australian Journal of International Affairs, 48(4), 507-518.

Kim, D. (2017). Navigating multiple archives across Southeast Asia: Three questions I wish I had known to ask. APSA-CD, 3(1).

King, N., \& Horrocks, C. (2016). Interviews in qualitative research. Los Angeles: Sage Publications.

Kobayashi, A. (1994). Coloring the field: Gender, "race", and the politics of fieldwork. Professional Geographer, 46(1), 73-80.

Kuhonta, E., Slater, D., \& Vu, T. (Eds). (2008). Southeast Asia in political science: Theory, region, and qualitative analysis. Stanford: Stanford University Press.

Leech, B. (2002). Symposium: Interview methods in political science. PS: Political Science and Politics, 35(4), 663-688.

Melvin, J. (2018). The army and the Indonesian genocide: Mechanics of mass murder. New York: Routledge.

Michael, G. (2015). Who's afraid of WikiLeaks? Missed opportunities in political science research. Review of Policy Research, 32(2), 175-199.

Mollet, J. (2011). Ethical issues in social sciece research in developing countries: Useful or symbolic. In R. Cribb (Ed.), Transmission of academic values in Asian Studies workshop (pp. 1-9). ANU, Canberra: Australia-Netherlands Research Collaboration.

Morgan, D. (1996). Focus groups. Annual Review of Sociology, 22(1), 129-152.

Newsome, A. (2014). Knowing when to scale back: Addressing questions of research scope in the field. PS: Political Science and Politics, 47(2), 410-413.

Perecman, E., \& Curran, S. (2006). A handbook for social science field research: Essays \& bibliographic sources on research design and methods. Thousand Oaks: Sage Publications.

Rempel, W. (1993). Delusions of a dictator: The mind of Marcos as revealed in his secret diaries. Boston: Little, Brown.

Rivera, S., Kozyreva, P., \& Sarovskii, E. (2002). Interviewing political elites: Lessons from Russia. PS: Political Science and Politics, 35(4), 683-688.

Shih, V. (2015). Research in authoritarian regimes: Transparency, tradeoffs and solutions. Qualitative and Multi-Method Research, 13(1), 20-22.

Smyth, F. (2012). CPJ journalist security guide: Covering the news in a dangerous and changing world. Committee to Protect Journalists. Retrieved from https://cpj.org/security/guide.pdf

Solinger, D. (2006). Interviewing Chinese people: From high-level officials to the unemployed. In M. Heimer \& S. Thogersen (Eds.), Doing fieldwork in China (pp. 153-167). Honolulu: University of Hawaii Press.

Sriram, C., King, J., Mertus, J., Martin-Ortega, O., \& Herman, J. (Eds). (2009). Surviving field research: Working in violent and difficult situations. New York: Routledge.

Wedeen, L. (2010). Reflections on ethnographic work in political science. Annual Review of Political Science, 13(1), 255-272.

Weiss, M., Hicken, A., \& Kuhonta, E. (2017). Doing political science in Southeast Asia: Field research, ethics, engagement, and employability. APSA-CD, 3(1).

West, S. (2015). New surveillance self-defense playlist for academic researchers. Retrieved from https://www.eff.org/deeplinks/2015/09/new-surveillance-self-defense-playlist-academicresearchers

Yin, R. (2003). Case study research: Design and methods ( $3^{\text {rd }}$ edition). Thousand Oaks: Sage Publications.

Zinn, M. (1979). Field research in minority communities: Ethical, methodological and political observations by an insider. Social Problems, 27(2), 209-219. 